\title{
Comparative study on long-term stability in mandibular sagittal split ramus osteotomy: hydroxyapatite/poly-L-lactide mesh versus titanium miniplate
}

\author{
Young-Wook Park ${ }^{*}$ (D, Hyun-Sik Kang and Jang-Ha Lee
}

\begin{abstract}
Background: Resorbable devices have recently been adopted in the field of orthognathic surgery with controversies about their postoperative skeletal stability. Hence, we determined the long-term skeletal stability of unsintered hydroxyapatite/poly-L-lactic acid (HA/PLLA) mesh for osteofixation of mandibular sagittal split ramus osteotomy (SSRO), and compared it with that of titanium miniplate.

Methods: Patients were divided into resorbable mesh and titanium miniplate fixation groups. A comparative study of the change in the mandibular position was performed with preoperative, 1-day, 6-month, and 2-year postoperative lateral cephalograms.

Results: At postoperative 6 months_compared with postoperative 1 day, point B (supra-mentale) was significantly displaced anteriorly in the titanium-fixation group. Moreover, at postoperative 2 years-compared with postoperative 6 months, point B was significantly displaced inferiorly in the titanium-fixation. However, the HA/PLLA mesh-fixation group did not show any significant change with respect to point B postoperatively.

Conclusions: The HA/PLLA mesh-fixation group demonstrated superior long-term skeletal stability with respect to the position of mandible, when compared with the titanium-fixation group.
\end{abstract}

Keywords: Mandibular SSRO, HA/PLLA mesh, Titanium miniplate, Long-term skeletal stability

\section{Background}

Osteofixation stability is one of the prerequisites for successful orthognathic surgery. Recently, the number of complicated surgeries requiring greater magnitude of segmental movements or segmental movements to the position of tissue resistance has increased for maxillofacial plastic and reconstructive surgeons. In particular, mandibular setback remains a more unstable movement than mandibular advancement [1]. Therefore, techniques of modern orthognathic surgery require greater osteofixation stability.

\footnotetext{
* Correspondence: ywpark@gwnu.ac.kr

Department of Oral and Maxillofacial Surgery, College of Dentistry, Gangneung-Wonju National University, 7 Jukheon-Gil, Gangneung, Gangwondo 25457, South Korea
}

For a long time, titanium plates and screws have been considered as the "gold standard" for rigid fixation in orthognathic surgery. Recently, general consensus has changed from routine removal of the titanium devices to leaving them in the body unless it causes any problems [2]. Although titanium binds to the bone, titanium plates and screws should be removed due to adverse effects to surrounding tissues [3], interference with radiological evaluation, and possible stress-shielding, as well as patient's request.

We can eliminate the potential need for a second operation by using resorbable osteosynthesis. To the best of our knowledge, the use of resorbable plates in the field of orthognathic surgery was first reported in 1998 [4]. To date, a lot of clinical studies have reported comparable results between the resorbable and titanium devices regarding postoperative skeletal stability and 
frequency of relapse [5-10]. Some surgeons pointed out the lack of segmental stability, especially in the early postoperative period of resorbable osteosynthesis [11].

However, recent innovative technology produced more rigid resorbable materials, such as unsintered hydroxyapatite/poly-L-lactic acid (HA/PLLA) [12]. In this study, we determined the long-term skeletal stability of HA/ PLLA mesh for osteofixation of mandibular SSRO, and compared it with that of titanium miniplate.

\section{Methods}

This study was approved by the institutional review board of Gangneung-Wonju National University Dental Hospital (IRB No. 2017-003). Orthognathic surgeries were performed by one surgeon between 2010 and 2014 . The inclusion criteria for patients were as follows:

1. Diagnosis of developmental dentofacial deformity without any congenital anomaly.

2. Mandibular prognathism with or without facial asymmetry.

3. History of mandibular or maxillomandibular surgery using mandibular bilateral SSRO (Obwegesser-Dal Pont technique).

4. History of concomitant advancement or straightening genioplasty.

5. Application of the same osteofixation system to the maxillary and mandibular osteofixation in case of maxillomandibular surgery.

Patients were divided into $0.5-\mathrm{mm}$, resorbable mesh (OsteotransMX ${ }^{\circ}$, Takiron, Osaka, Japan; group 1) and 2.0-mm, 4-hole titanium miniplate ( $\mathrm{M}^{\circ}$, Osteomed Co., Addison, TX, USA; group 2) fixation groups. For resorbable-osteofixation of mandibular SSRO, 3-5 resorbable screws with $5.0-\mathrm{mm}$ length were engaged in each segment. Then, $0.5-\mathrm{mm}$ unsintered-HA/PLLA mesh was easily bendable in room temperature to fit the contour of mandibular SSRO site. For titanium-osteofixation, $6.0-\mathrm{mm}$ titanium screws were used (Fig. 1). In the case of maxillomandibular surgery, all patients had undergone surgical alterations of maxilla with unilateral impaction and/or posterior impaction. A comparative study of the change in the mandibular position was performed with preoperative (T1), 1-day (T2), 6-month (T3), and 2-year (T4) postoperative lateral cephalograms using a photoanalysis software Xelis dental ${ }^{\circ}$ (Infinity care, Seoul, Korea). We set up eight reference points (Fig. 2a) and six measuring parameters (Fig. 2b) in consecutive lateral cephalograms. We used FH plane (porion; Po-orbitale; Or) as the horizontal reference line (HRL), and the vertical reference line (VRL) was defined as the line perpendicular to FH plane over Sella (S) point.

All statistical analyses were done by using IBM SPSS statistics version 23 (IBM Co., NY, USA). The differences between $\mathrm{T} 1$ and $\mathrm{T} 2$ (T2-T1) determined the surgical change, the differences between T2 and T3 (T3-T2) determined the short-term relapse, and the differences between T3 and T4 (T4-T3) determined the long-term relapse after operation. The Wilcoxon rank sum test was applied to analyze the surgical change, as well as short-term and long-term relapses. Moreover, the Mann-Whitney test was applied to analyze the differences between the groups at each time point. Values of $p<0.05$ were considered significant.

\section{Results}

A total of 30 patients (16 males and fourteen females) were enrolled in this study. Patients' basic information is summarized in Table 1. Clinically, no patient experienced operative complications.

\section{Preoperative stage}

On the presurgical stage, no statistical differences were checked in each parameter between the two groups

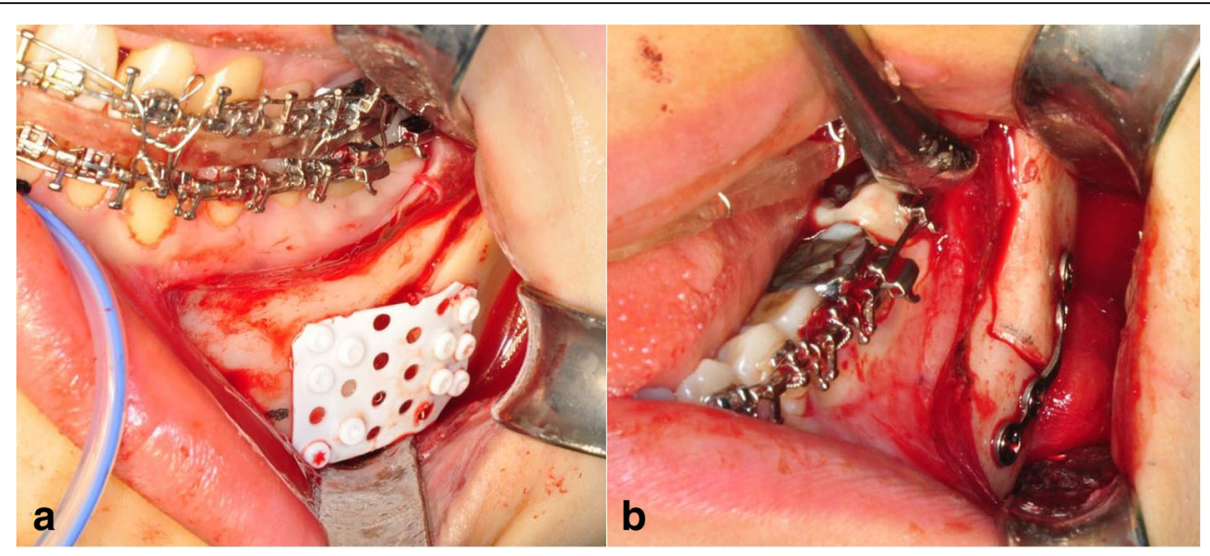

Fig. 1 Clinical situations of resorbable HA/PLLA mesh (a) and titanium miniplate (b) osteofixation in SSRO 


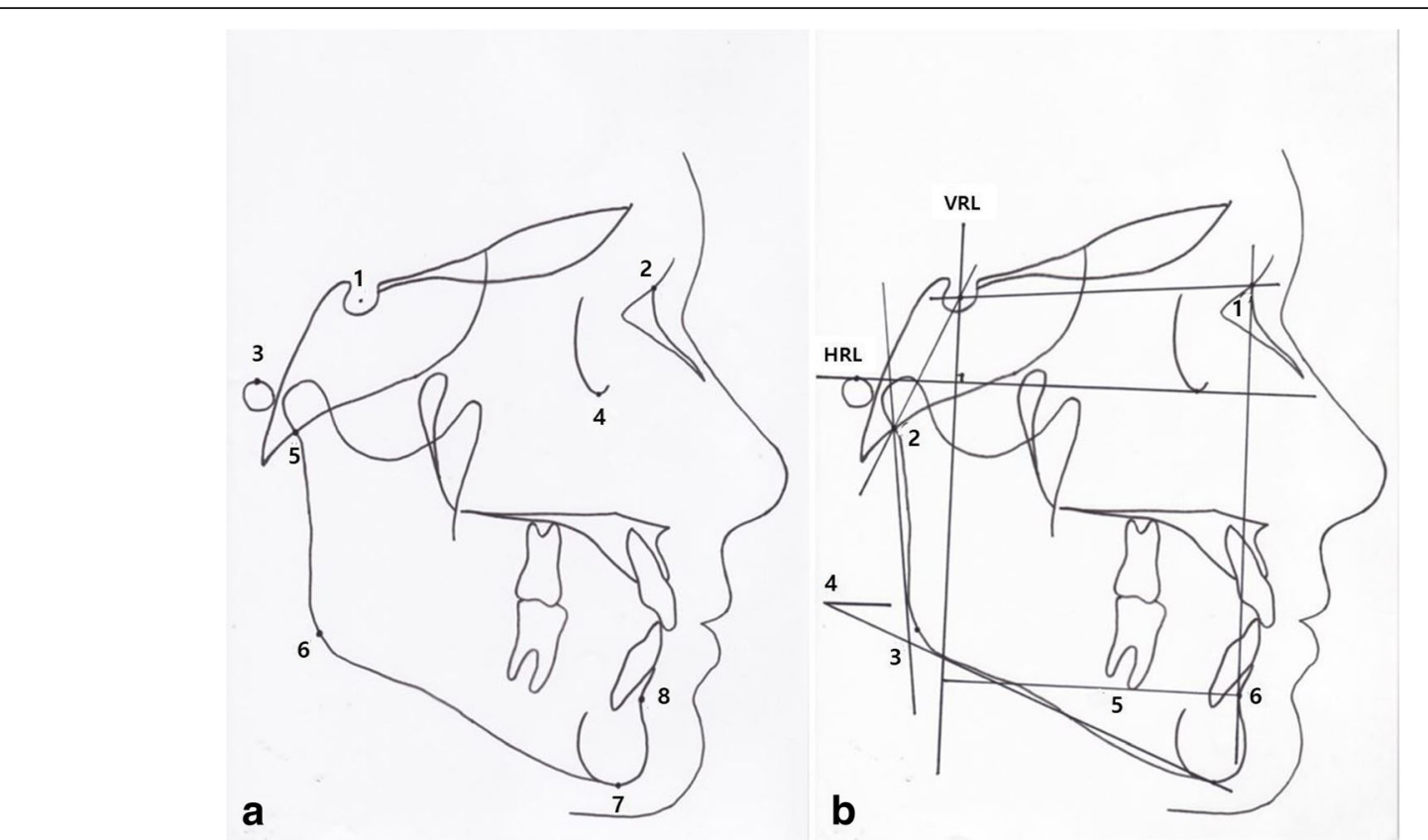

Fig. 2 a Reference points used in this study: 1. Sella (S); 2. Nasion (N); 3. Porion (Po); 4. Orbitale (Or); 5. Articulare (Ar); 6. Gonion (Go); 7. Menton $(\mathrm{Me})$; 8. Supramentale (B). b Measuring parameters used in this study: 1. SNB $\left({ }^{\circ}\right)$; 2. Articular angle $\left({ }^{\circ}\right)$; 3. Gonial angle $\left({ }^{\circ}\right)$; 4 . Mandibular plane angle to FH ( $\left.{ }^{\circ}\right)$; 5. VRL-B (mm); 6. HRL-B (mm)

(Table 2). Therefore, there were no significant differences with respect to the skeletal characteristics between the two groups.

\section{Surgical change (T2-T1)}

After the operation, point B was moved posterosuperiorly according to the surgical change of the mandibular setback and maxillary impaction. SNB was also significantly decreased in both groups. Otherwise, articular angle, gonial angle, and mandibular plane angle revealed no significant differences in both groups (Table 3).

\section{Short-term relapse (T3-T2)}

At postoperative 6 months, point B moved to a horizontally anterior position in both groups. However, statistical significance was detected only in group 2 (titanium-fixation group). SNB was also significantly increased in group 2, which indicated short-term relapse. Otherwise, the gonial angle was significantly increased in both groups, and the mandibular plane angle was significantly increased in group 1 (Table 4).

\section{Long-term relapse (T4-T3)}

At postoperative 2 years, point B moved to a vertically inferior position in group 2. Other parameters did not show any significant differences between the two groups, and compared with postoperative 6 months (Table 5).

\section{Discussion}

Resorbable devices have increasingly been adopted in orthognathic surgery as it eliminates the necessity for patients to undergo a second-stage removal surgery. However, it is worth noting that one of the disadvantages of resorbable devices is the lack of rigidity.

Table 1 Patient's information

\begin{tabular}{lll}
\hline & $\begin{array}{l}\text { Resorbable mesh group } \\
(n=16)\end{array}$ & $\begin{array}{l}\text { Titanium miniplate group } \\
(n=14)\end{array}$ \\
\hline $\begin{array}{l}\text { Age (years) } \\
\text { Gender }\end{array}$ & $22.8 \pm 3.1$ & $22.9 \pm 5.1$ \\
Male & 7 & 9 \\
Female & 9 & 5 \\
Number of patients & $5(2)$ & $7(5)$ \\
Mandible (genioplasty) & $11(5)$ & $7(2)$ \\
Maxillomandible (genioplasty) & & \\
\hline
\end{tabular}


Table 2 Comparison of absorbable group and titanium group on the presurgical stage

\begin{tabular}{|c|c|c|c|c|c|}
\hline \multirow[t]{2}{*}{ Parameters } & \multicolumn{2}{|c|}{ Absorbable group $(n=16)$} & \multicolumn{2}{|c|}{ Titanium group $(n=14)$} & \multirow[t]{2}{*}{$P$ value } \\
\hline & Mean & SD & Mean & SD & \\
\hline \multicolumn{6}{|l|}{ Horizontal measurements } \\
\hline VRP-B (mm) & 56.83 & 8.17 & 52.10 & 7.96 & 0.759 \\
\hline \multicolumn{6}{|l|}{ Vertical measurements } \\
\hline HRP-B (mm) & 80.80 & 7.03 & 79.16 & 8.75 & 0.697 \\
\hline \multicolumn{6}{|l|}{ Angular measurements } \\
\hline SNB & 82.26 & 4.90 & 78.66 & 3.71 & 0.637 \\
\hline Articular angle & 138.05 & 7.59 & 136.04 & 7.17 & 0.313 \\
\hline Gonial angle & 128.94 & 8.12 & 127.35 & 5.07 & 0.822 \\
\hline Mandibular plane angle & 34.27 & 6.88 & 33.28 & 6.70 & 0.667 \\
\hline
\end{tabular}

Mann-Whitney test

However, a lot of clinical studies reported a predictable rigid osteosynthesis with the use of polymers of poly-lactic acid [13-15]. In our long-term follow-up study, we have induced a meaningful data, suggesting that HA/PLLA mesh-osteofixation may be superior to titanium miniplate-osteofixation at the mandibular SSRO site. In our previous animal experiment, we reproduced the clinical situations of HA/PLLA mesh and titanium miniplate-osteofixation after creating a discontinuity defect on rabbit mandible. Through it, we confirmed similar results with this clinical study in terms of recovery of functional rehabilitation evaluated by daily feed intake amount, and incidences of malocclusion and screw loosening [16].

In this study, a total of 30 patients were included. Their skeletal characteristics did not show any significant differences between the experimental (resorbable mesh) and control (titanium miniplate) groups. Eleven out of 16 patients in the experimental group and 7 out of 14 patients in the control group underwent maxillary posterior impaction and mandibular setback. The osteotomy line for genioplasty was located under the supramentale (point B). Therefore, point B was moved posteriorly and superiorly after surgery, regardless of accompanying genioplasty. Therefore, the significant change of point B in the titanium miniplate group indicates relapse tendency. Moreover, the significant changes of gonial angle and mandibular plane angle at postoperative 6 months seem to indicate complex results of segmental remodeling, adaptive change of temporomandibular joints, and postoperative orthodontics.

HA/PLLA mesh, which was used in this study, is a nanocomposite consisting of unsintered hydroxyapatite and carbonate ion combined with poly-L-lactide. A study reported unsintered-HA/PLLA nanocomposite maintains a bending strength equal to that of human cortical bone for 25 weeks in vivo [17]. Furthermore, the bending strength was maintained at 52 weeks in the subcutis of the rabbit [18]. Therefore, it seems to provide a stable segmental stability, similar to titanium miniplate

Table 3 Comparison of surgical change (T2-T1) on absorbable group and titanium group

\begin{tabular}{|c|c|c|c|c|c|}
\hline \multirow[t]{2}{*}{ Parameters } & \multicolumn{2}{|c|}{ Absorbable group $(n=16)$} & \multicolumn{2}{|c|}{ Titanium group $(n=14)$} & \multirow[t]{2}{*}{$P$ value } \\
\hline & $\overline{M e a n}$ & $P$ value & Mean & $P$ value & \\
\hline \multicolumn{6}{|l|}{ Horizontal measurements } \\
\hline VRP-B (mm) & $-7.39 \pm 4.53$ & $0.000+$ & $-7.18 \pm 4.85$ & $0.001+$ & 0.854 \\
\hline \multicolumn{6}{|l|}{ Vertical measurements } \\
\hline HRP-B (mm) & $-2.35 \pm 4.07$ & $0.044+$ & $-2.35 \pm 4.29$ & 0.055 & 0.951 \\
\hline \multicolumn{6}{|l|}{ Angular measurements } \\
\hline SNB & $-3.74 \pm 1.73$ & $0.000+$ & $-4.69 \pm 3.12$ & $0.002+$ & 0.355 \\
\hline Articular angle & $2.97 \pm 6.08$ & 0.098 & $0.79 \pm 5.57$ & 0.660 & 0.377 \\
\hline Gonial angle & $-0.57 \pm 6.47$ & 0.453 & $-1.78 \pm 5.30$ & 0.198 & 0.697 \\
\hline Mandibular plane angle & $1.13 \pm 3.17$ & 0.179 & $0.59 \pm 2.40$ & 0.140 & 0.580 \\
\hline
\end{tabular}

Wilcoxon rank sum test

Mann-Whitney test

$P=0.05$

$\dagger=$ Significant difference 
Table 4 Comparison of post-surgical change (T3-T2) on absorbable group and titanium group

\begin{tabular}{|c|c|c|c|c|c|}
\hline \multirow[t]{2}{*}{ Parameters } & \multicolumn{2}{|c|}{ Absorbable group $(n=16)$} & \multicolumn{2}{|c|}{ Titanium group $(n=14)$} & \multirow[t]{2}{*}{$P$ value } \\
\hline & Mean & $P$ value & Mean & $P$ value & \\
\hline \multicolumn{6}{|l|}{ Horizontal measurements } \\
\hline VRP-B (mm) & $1.94 \pm 3.61$ & 0.063 & $2.86 \pm 3.55$ & $0.017+$ & 0.580 \\
\hline \multicolumn{6}{|l|}{ Vertical measurements } \\
\hline HRP-B (mm) & $-0.95 \pm 2.63$ & 0.173 & $-0.87 \pm 3.10$ & 0.397 & 0.984 \\
\hline \multicolumn{6}{|l|}{ Angular measurements } \\
\hline SNB & $0.70 \pm 1.25$ & 0.056 & $1.61 \pm 1.41$ & $0.001+$ & 0.154 \\
\hline Articular angle & $-2.15 \pm 3.94$ & 0.215 & $-0.28 \pm 4.45$ & 0.975 & 0.166 \\
\hline Gonial angle & $4.77 \pm 5.20$ & $0.006+$ & $2.53 \pm 4.35$ & $0.048+$ & 0.423 \\
\hline Mandibular plane angle & $1.94 \pm 3.43$ & $0.039+$ & $0.65 \pm 2.78$ & 0.363 & 0.423 \\
\hline
\end{tabular}

Wilcoxon rank sum test

Mann-Whitney test

$P=0.05$

$\dagger=$ Significant difference

osteosynthesis [19]. Furthermore, in this study, resorbable mesh-osteofixation, which allows greater screw installation, demonstrated increased reliable horizontal stability than titanium miniplate-osteofixation at postoperative 6 months. This is probably because three to five screws were engaged at each segment after SSRO for resorbable mesh-osteofixation.

For our patients, titanium miniplates were removed about 6 months after the operation. However, the resorbable mesh is supposed to be biodegraded with body fluids and display osteoconduction due to the well-known properties of HA. The biodegradation period was reported to be 4.5-5.5 years [20]. At postoperative 2 years, the mechanical strength of HA/PLLA mesh was almost lost, but still-to some extent-maintained. This is why HA/PLLA mesh-osteofixation demonstrated more reliable vertical stability than titanium miniplate-osteofixation at postoperative 2 years. During the degradation period, a localized inflammation had developed in one patient in group 1, which was controlled unevenfully by surgical debridement and antibiotics. Rarely, metabolic products of poly-lactic acid may trigger a foreign-body inflammatory reaction [21].

Another advantage of HA/PLLA mesh is its compact design. From the authors' experience with polymers of PLLA, larger devices, such as a $2.4 \mathrm{~mm}$, 6-hole plate, should be used to achieve a stability at the SSRO site [22]. It may sometimes be palpable after operation when the patient has thin skin. However, in this clinical study, we have adopted a 0.5 -mm-thick mesh that is easily cut and adaptable at the SSRO site. The limitations of our study is that the number of samples is very small and various surgical methods which likely to affect on the results were performed.

Table 5 Comparison of long-term result change (T4-T3) on absorbable group and titanium group

\begin{tabular}{|c|c|c|c|c|c|}
\hline \multirow[t]{2}{*}{ Parameters } & \multicolumn{2}{|c|}{ Absorbable group $(n=16)$} & \multicolumn{2}{|c|}{ Titanium group $(n=14)$} & \multirow[t]{2}{*}{$P$ value } \\
\hline & $\overline{M e a n}$ & $P$ value & Mean & $P$ value & \\
\hline \multicolumn{6}{|l|}{ Horizontal measurements } \\
\hline VRP-B (mm) & $0.28 \pm 2.44$ & 0.605 & $-0.65 \pm 3.81$ & 0.975 & 0.728 \\
\hline \multicolumn{6}{|l|}{ Vertical measurements } \\
\hline HRP-B (mm) & $0.33 \pm 2.10$ & 1.000 & $1.38 \pm 2.36$ & $0.048+$ & 0.142 \\
\hline \multicolumn{6}{|l|}{ Angular measurements } \\
\hline SNB & $0.20 \pm 0.80$ & 0.816 & $0.00 \pm 0.64$ & 0.683 & 1.000 \\
\hline Articular angle & $-1.14 \pm 3.73$ & 0.148 & $-0.22 \pm 2.90$ & 0.754 & 0.790 \\
\hline Gonial angle & $0.25 \pm 2.28$ & 0.365 & $-0.19 \pm 2.07$ & 0.778 & 0.423 \\
\hline Mandibular plane angle & $0.58 \pm 1.22$ & 0.121 & $-0.30 \pm 1.74$ & 0.397 & 0.064 \\
\hline
\end{tabular}

Wilcoxon rank sum test

Mann-Whitney test

$P=0.05$

$\dagger=$ Significant difference. 


\section{Conclusions}

Titanium miniplate-osteofixation of the SSRO site revealed short-term horizontal and long-term vertical relapse in mandibular position in patients with mandibular prolaterognathism. However, HA/PLLA mesh-osteofixation of SSRO site demonstrated stable mandibular position postoperatively. Therefore, we can induce a greater reliable skeletal stability by using mesh-type resorbable device. This may be the case since resorbable mesh has spatial advantage in terms of screw installation, which could be confirmed by a finite element method.

\section{Abbreviation}

n: Number

\section{Acknowledgements}

None.

\section{Funding}

No funding was needed.

\section{Availability of data and materials}

Please contact author for data requests.

\section{Authors' contributions}

HSK prepared the first draft of the manuscript and assisted in English editing. $J H L$ performed the clinical study. YWP performed the surgery as the operator and revised the manuscript. All authors read and approved the final manuscript.

\section{Ethics approval and consent to participate}

This study was approved by the institutional review board of GangneungWonju National University Dental Hospital (IRB No. 2017-003).

\section{Consent for publication}

Written informed consent was obtained from the patients or patient's guardian for including the data of radiographic images in this study.

\section{Competing interests}

The authors declare that they have no competing interests.

\section{Publisher's Note}

Springer Nature remains neutral with regard to jurisdictional claims in published maps and institutional affiliations.

Received: 23 November 2018 Accepted: 4 February 2019

Published online: 01 March 2019

\section{References}

1. Ko EW, Huang CS, Lo LJ, Chen YR (2013) Alteration of masticatory electromyographic activity and stability of orthognathic surgery in patients with skeletal class III malocclusion. J Oral Maxillofac Surg 71(7):1249-1260

2. Haug RH (1996) Retention of asymptomatic bone plates used for orthognathic surgery and facial fractures. J Oral and Maxillofac Surg 54(5): 611-617

3. Jorgenson DS, Mayer MF, Ellenbogen RG, Centeno JA, Johnson FB, Mullick FG, Manson PN (1997) Detection of titanium in human tissues after craniofacial surgery. Plast Reconstr Surg 99:976-979

4. Haers PE, Sailer HF (1998) Biodegradable self-reinforced poly-L/DL-lactide plates and screws in bimaxillary orthognathic surgery: short term skeletal stability and material related failures. J Craniomaxillofac Surg 26(6):363-372

5. Cheung LK, Chow LK, Chiu WK (2004) A randomized controlled trial of resorbable versus titanium fixation for orthognathic surgery. Oral Surgery, Oral Med, Oral Pathol, Oral Radiol, Endodontol 98(4):386-397

6. Landes CA, Ballon A (2006) Skeletal stability in bimaxillary orthognathic surgery: $\mathrm{P}$ (L/DL) LA-resorbable versus titanium osteofixation. Plast Reconstr Surg 118(3):703-721
7. Landes CA, Ballon A, Sader R (2007) Segment stability in bimaxillary orthognathic surgery after resorbable poly (L-lactide-co-glycolide) versus titanium osteosyntheses. J Craniofac Surg 18(5):1216-1229

8. Stockmann P, Böhm H, Driemel O, Mühling J, Pistner H (2010) Resorbable versus titanium osteosynthesis devices in bilateral sagittal split ramus osteotomy of the mandible-he results of a two centre randomised clinical study with an eight-year follow-up. J Craniomaxillofac Surg 38(7):522-528

9. Ueki K, Okabe K, Miyazaki M, Mukozawa A, Moroi A, Marukawa K, Nakagawa K, Yamamoto E (2011) Skeletal stability after mandibular setback surgery: comparisons among unsintered hydroxyapatite/poly-L-lactic acid plate, poly-Llactic acid plate, and titanium plate. J Oral and Maxillofac Surg 69(5):1464-1468

10. Paeng JY, Hong J, Kim CS, Kim MJ (2012) Comparative study of skeletal stability between bicortical resorbable and titanium screw fixation after sagittal split ramus osteotomy for mandibular prognathism. J Craniomaxillofac Surg 40(8):660-664

11. Matthews N, Khambay B, Ayoub A, Koppel D, Wood G (2003) Preliminary assessment of skeletal stability after sagittal split mandibular advancement using a bioresorbable fixation system. Br J Oral and Maxillofac Surg 41(3):179-184

12. Shikinami Y, Okuno M (2001) Bioresorbable devices made of forged composites of hydroxyapatite (HA) particles and poly-L lactide (PLLA): part II. Practical properties of miniscrews and miniplates. Biomaterials 22:3179-3211

13. Mazzonetto R, Paza A, Spagnoli D (2004) A retrospective evaluation of rigid fixation in orthognathic surgery using a biodegradable self-reinforced (70L: 30DL) polyactide. Int J Oral and Maxillofac Surg 33(7):664-669

14. Ueki K, Nakagawa K, Marukawa K, Takazakura D, Shimada M, Takatsuka S, Yamamoto E (2005) Changes in condylar long axis and skeletal stability after bilateral sagittal split ramus osteotomy with poly-L-lactic acid or titanium plate fixation. Int J Oral and Maxillofac Surg 34(6):627-634

15. Moure C, Qassemyar Q, Dunaud O, Neiva C, Testelin S, Devauchelle B (2012) Skeletal stability and morbidity with self-reinforced $\mathrm{P}(\mathrm{L} / \mathrm{DL}) \mathrm{LA}$ resorbable osteosynthesis in bimaxillary orthognathic surgery. J Craniomaxillofac Surg 40(1):55-60

16. Kim MK, Park YW (2018) Experimental study on segmental stability of mandibular osteotomy: Bioresorbable mesh versus titanium osteosynthesis. Oral Biol Res 42(3):121-129

17. Shikinami Y, Okuno M (1999) Biodegradable devices made of forged composites of hydroxyapatite (HA) particles and poly-L lactide (PLLA): part I. Basic characteristics. Biomaterials 20:859-877

18. Furukawa $T$, Matsusue $Y$, Yasunaga $T$, Shikinami $Y$, Okuno $M$, Nakamura $T$ (2000) Biodegradation behavior of ultra-high-strength hydroxyapatite/poly (L-lactide) composite rods for internal fixation of bone fractures. Biomaterials 21(9):889-898

19. Landes CA, Ballon A, Tran A, Ghanaati S, Sader R (2014) Segment stability in orthognathic surgery: hydroxyapatite/poly L-lactide osteoconductive composite versus titanium miniplate osteosyntheses. J Craniofac Surg 41: 930-942

20. Shikinami Y, Matsusue $Y$, Nakamura T (2005) The complete process of biodegradation and bone replacement using devices made of forged composites of raw hydroxyapatite particles/ poly-L lactide (F-u-HA; PLLA). Biomaterials 26:5542-5551

21. Mackool R, Yim J, McCarthy JG (2006) Delayed degradation in a resorbable plating system. J Craniofac Surg 17(1):194-197

22. Park JM, Park YW (2010) Postoperative stability of fixation with absorbables in simultaneous maxillomandibular orthognathic surgery. Maxillofac Plast Reconstr Surg 32(2):126-131 